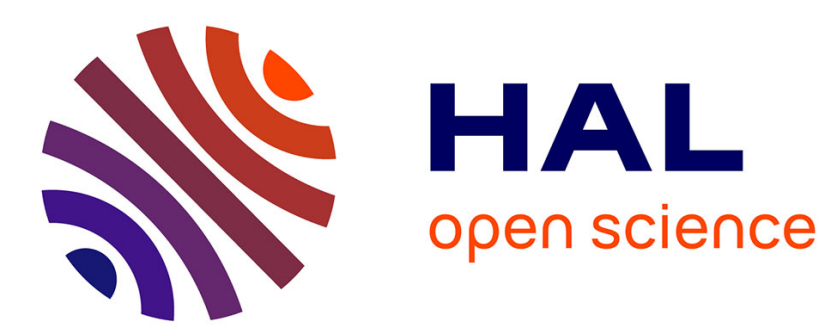

\title{
Imaging of magnetic surfaces by detection of photothermally modulated stray fields
}

\author{
D. Hoppstädter, U. Netzelmann
}

\section{To cite this version:}

D. Hoppstädter, U. Netzelmann. Imaging of magnetic surfaces by detection of photothermally modulated stray fields. Journal de Physique IV Proceedings, 1994, 04 (C7), pp.C7-659-C7-662. 10.1051/jp4:19947156 . jpa-00253215

\section{HAL Id: jpa-00253215 https://hal.science/jpa-00253215}

Submitted on 1 Jan 1994

HAL is a multi-disciplinary open access archive for the deposit and dissemination of scientific research documents, whether they are published or not. The documents may come from teaching and research institutions in France or abroad, or from public or private research centers.
L'archive ouverte pluridisciplinaire HAL, est destinée au dépôt et à la diffusion de documents scientifiques de niveau recherche, publiés ou non, émanant des établissements d'enseignement et de recherche français ou étrangers, des laboratoires publics ou privés. 


\title{
Imaging of magnetic surfaces by detection of photothermally modulated stray fields
}

D. Hoppstädter and U. Netzelmann

Fraunhofer-Institute for Nondestructive Testing (IzfP), University, Bldg. 37, 66123 Saarbrücken, Germany

\begin{abstract}
Images from surfaces of ferro- and ferrimagnetic solids are obtained by photothermal modulation of magnetic properties by a focused laser beam and by measuring the surface stray fields using a sensor coil. The lateral resolution is about $10 \mu \mathrm{m}$. The method was applied to a sample consisting of cementite plates in an austenite matrix and to monocrystalline ferrite material for video recording heads. Amplitude and phase images are influenced strongly by external magnetic fields. The signal is increasing slightly as a function of the modulation frequency.
\end{abstract}

\section{INTRODUCTION}

Characterisation of the microstructure of materials is a field of increasing importance in materials evaluation and nondestructive testing. Existing techniques for imaging magnetic surface properties are often requiring careful sample preparation. Photothermal techniques can offer an interesting alternative when a lateral resolution in the micron range is sufficient. Photothermal modulation of material properties has been used previously for improvement of lateral resolution in eddy current testing $\left(^{l}\right)$ or in ferromagnetic resonance experiments $\left({ }^{2}\right)$. We report on a new technique where we modulate magnetic properties of ferro- and ferrimagnetic materials with a chopped laser beam.

\section{EXPERIMENTAL}

A small pickup coil is used to measure the changes of the magnetic stray flux close to the surface, which are induced by the periodic light modulation (Fig. 1). The coil has an inner diameter of $1.2 \mathrm{~mm}$ and a typical distance of $0.2 \mathrm{~mm}$ from the surface. For amplification of the signal and for mechanical protection, the coil is embedded in a ferrite yoke, although signals can also be detected without yoke. The heating beam is focused through the bore of the yoke down to a radius of $4 \mu \mathrm{m}$. The signal is detected by a lock-in amplifier. By raster scanning the sample, amplitude and phase images of the surface can be produced.

\section{MEASUREMENTS AND RESULTS}

The photothermally modulated stray field (PMS) measurement was applied to a polished sample consisting of cementite plates (ferromagnetic, $T_{c}=215 \mathrm{C}$ ) with lengths of 1 to $3 \mathrm{~mm}$ and thicknesses of $200 \mu \mathrm{m}$ in an austenite matrix. The sample has a rectangular shape and was thermally thick. 


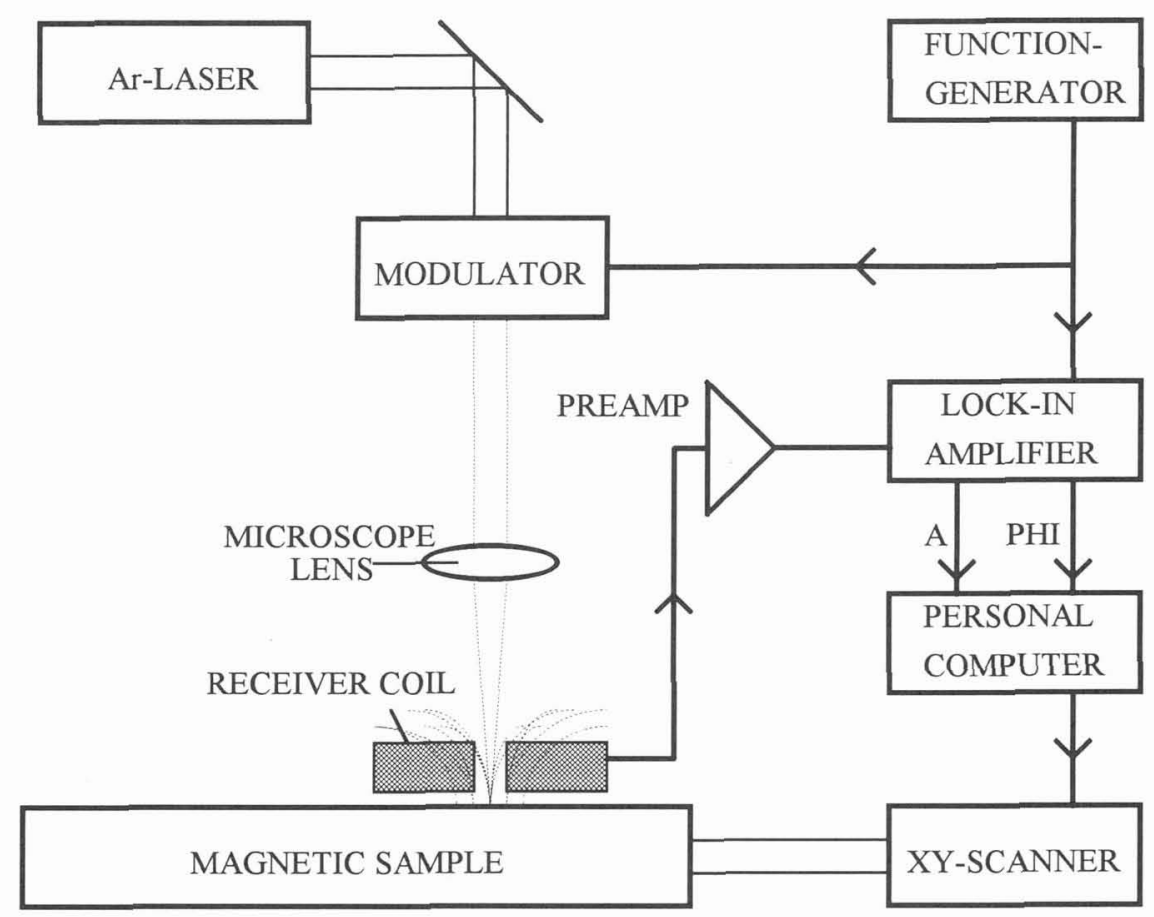

Fig. 1: Schematic diagram of the photothermally modulated stray field (PMS) technique

With the laser spot on the ferromagnetic plates, a coil signal of a few hundred nanovolts could be obtained with an absorbed power of $50 \mathrm{~mW}$ at a modulation frequencies between $100 \mathrm{~Hz}$ and $30 \mathrm{kHz}$. Fig. 2 shows an amplitude and a phase image at $3 \mathrm{kHz}$ of an area of $2 \mathrm{~mm} \times 2 \mathrm{~mm}$ of the sample. In the upper right corner, two cementite needles crossing at an angle of about $40^{\circ}$ can be observed, which appear with almost the same amplitude, but are $180^{\circ}$ out of phase. Other needles, which are visible in the optical micrograph, do not appear in the PMS image. This can be interpreted by different orientations of the magnetisation vectors in the needles, as the pickup coil measures mainly the time dependent stray field components perpendicular to the surface. Applying an external magnetic field in opposite directions results in an inversion of the phase contrast.

A theoretical estimation of the signal shows that the temperature dependent magnetisation $\mathrm{M}$ of the sample is the dominant mechanism for signal generation. The thermally modulated volume is modelled by a magnetic dipole source inducing a signal in the receiver coil. Taking the temperature amplitude from a 3-D calculation, reading $\mathrm{dM} / \mathrm{dT}$ from the known $\mathrm{M}(\mathrm{T})$, and considering the geometry of the coil, values of the induced voltage are calculated in good agreement with the experiment. At higher laser powers nonlinearities are observed, which are occurring when the Curie temperature is locally exceeded in the centre of the laser spot.

Fig. 3 shows the dependence of the signal on the modulation frequency from a selected spot on the cementite plate. The signal is increasing roughly proportional to $\log (\omega)$. According to the induction law, the signal amplitude should increase linearly with the modulation frequency. This behaviour is modified by the frequency dependence of the thermal modulation. As long as the thermal diffusion length is large compared with the heating beam diameter, the surface temperature oscillation in the centre of the heating spot is almost independent of the frequency $\left({ }^{3}\right)$. At higher frequencies it will become frequency dependent, finally exhibiting a behaviour $\sim \omega^{-0.5}$. 


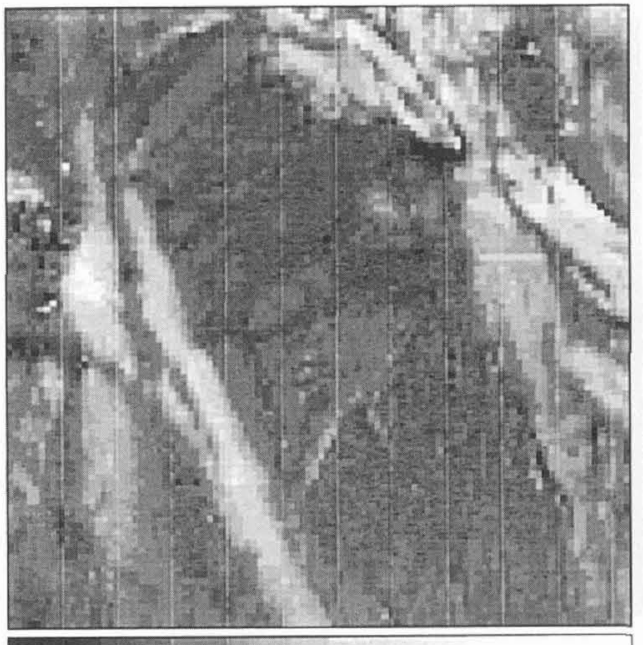

Q. 0

Amplitude Ca.u.

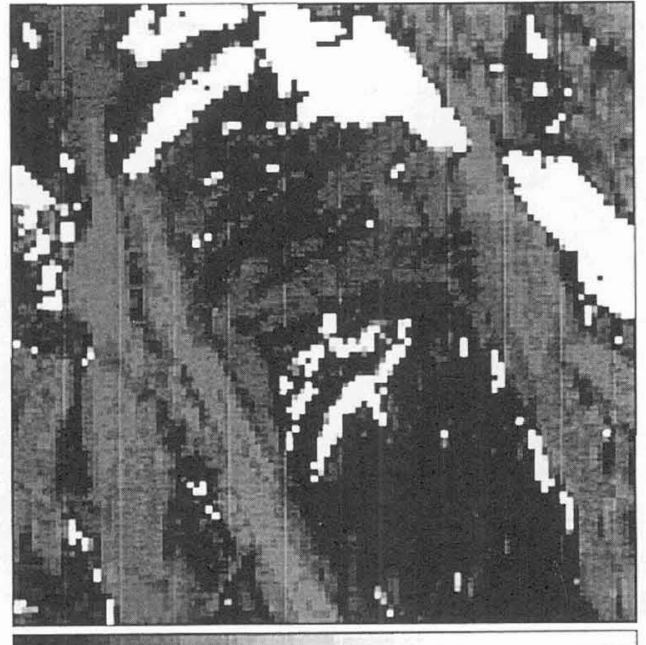

0. $0^{\circ}$

$180.0^{\circ}$

$-180.9$

Phase (deg.)

Fig. 2: PMS amplitude (left) and phase (right) image of a cementite/austenite sample

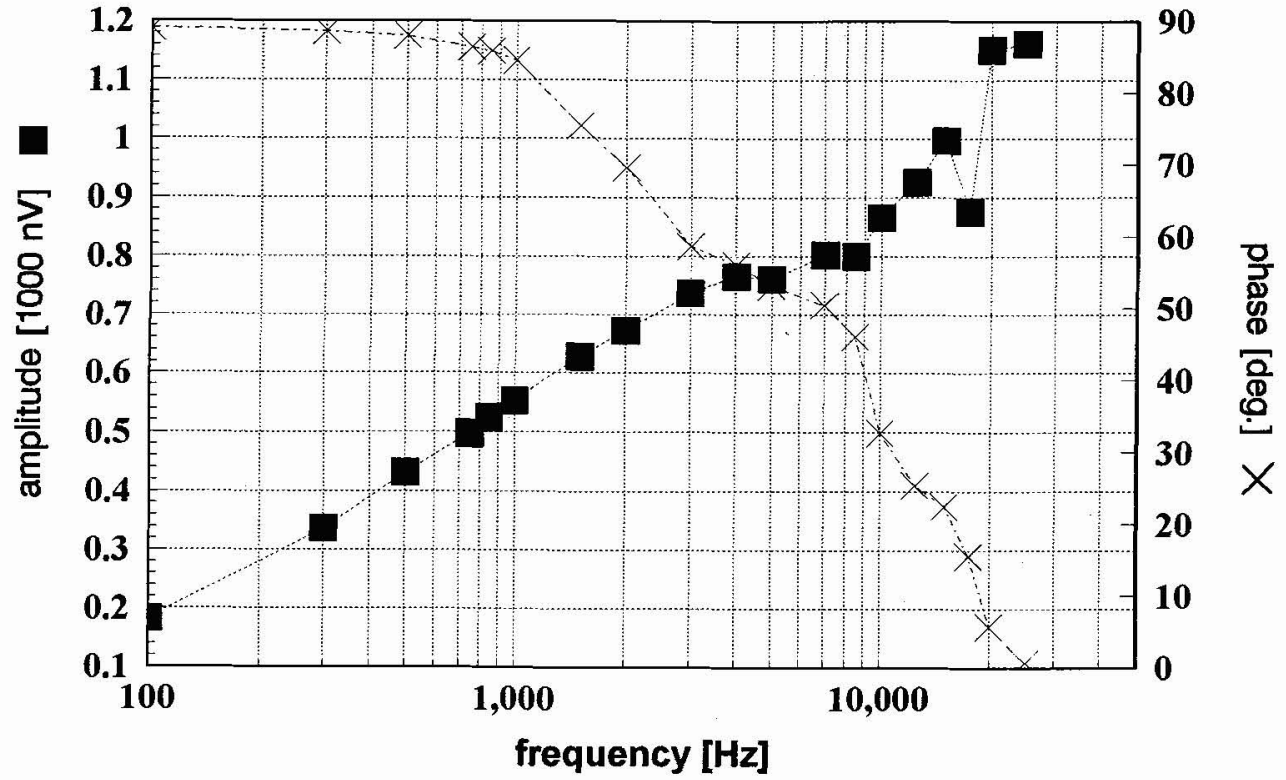

Fig. 3; Frequency dependence of the PMS signal of a cementite plate

Due to shape of the magnetisation curve $\mathrm{M}(\mathrm{T})$ as a function of temperature $(|\partial \mathrm{M} / \partial \mathrm{T}|$ is becoming larger when approaching the Curie temperature), the volume integrated oscillation of the magnetisation does not exactly behave as the volume integrated temperature oscillation $\left(\sim \omega^{-1}\right)$. The centre of the heated zone is pronounced in the integration due to the static temperature distribution in the spot. The volume integrated oscillation of the magnetisation will vary with exponents between 0 and -1 as a function of the frequency. This explains why the coil signal is only slightly increasing with increasing frequency. A more quantitative analysis is in progress. 


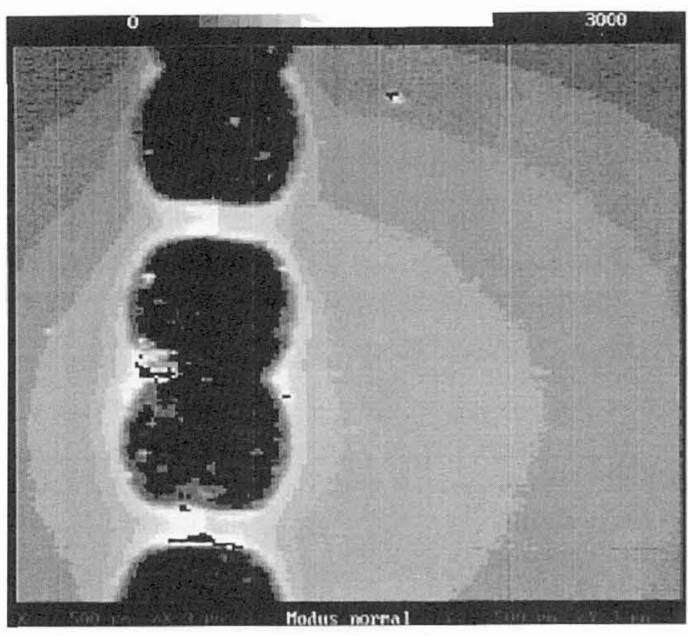

Fig. 4: Thermal wave amplitude image of a raw material for video recording heads.

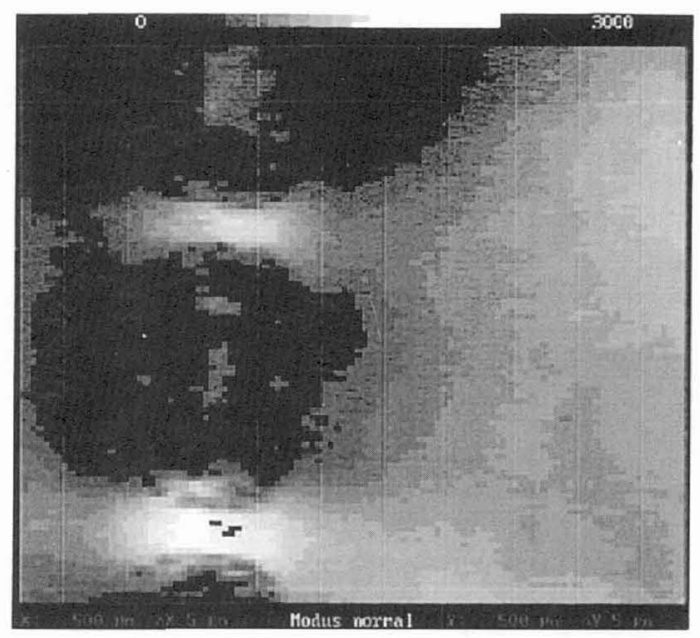

Fig. 5: Photothermally modulated stray field amplitude image of the same area

The second sample was a raw state video recording head material consisting of monocrystalline $\mathrm{MnZn}$ ferrite. Two ferrite blocks are joined together, with small bridges machined into the material finally forming the yokes of the heads. Fig. 5 shows the thermal wave amplitude image obtained by photothermal radiometry with two yokes visible as bright structures (high amplitude) in the left part. The image size is $500 \mu \mathrm{m} \times 500 \mu \mathrm{m}$. The corresponding PMS image is shown in Fig. 5. Its contrast is different from Fig. 4. For example, not all zones of high thermal wave amplitude do appear in the magnetic image. Instead, regions are emphasised where the magnetic flux is concentrated, namely at the yokes. The upper yoke appears with a weaker signal than the lower one, which could be due to a magnetic inhomogeneity.

\section{CONCLUSION}

Photothermally modulated stray field measurements allow one to image surfaces of magnetic materials and components with a lateral resolution of $10 \mu \mathrm{m}$, which is determined by the diameter of the heating beam. The depth profiling capability of the photothermal techniques should make the technique applicable to samples with thin non-magnetic coatings. The method is contact-free and can be applied with surface roughnesses readily offered by many technical materials.

\section{REFERENCES}

[1] Moulder, J. C., Nakagawa, N., No, K. S., Lee, Y. P., Mc Clelland, J. F., Rev. Progr. Quant. NDE 8, Thompson, D. O., and Chimenti, D. E. (eds.), (Plenum Press, New-York 1989) p. 599

[2] Orth, T., Netzelmann, U., and Pelzl, J., Appl. Phys. Lett. 53 (1988) 1979

[3] Opsal, J., Rosencwaig, A., and Willenbourg, D., Appl. Optics 22 (1983) 3169 